\title{
Olhando para trás: um novo caminho possível para a descoberta de drogas em psicofarmacologia
}

\author{
Edward Shorter*
}

\section{INTRODUÇÃO}

Em vista da atual desaceleração no desenvolvimento de psicotrópicos inovadores, tem sido observado um crescente interesse na revisão de compostos do passado que foram bem-sucedidos, mas que agora estão esquecidos $^{1}$. A idéia não é reciclar os golden oldies, mas determinar o perfil de ação em receptores das drogas com eficácia comprovada que foram esquecidas e determinar quais os compostos patenteáveis que podem apresentar um perfil similar de receptores. Desde a introdução da psicofarmacologia moderna, com os primeiros ensaios de clorpromazina em 1952, milhares de compostos já foram sintetizados. Muitos desses demonstraram eficácia em ensaios clínicos abertos ou em casos isolados, apenas para serem deixados de lado por erros do tipo II resultantes de ensaios controlados sem poder estatístico suficiente, freqüentemente com

Original em inglês publicado em Nature Rev, v.1. @ 2002 Nature Publishing Group. Tradução publicada com autorização do autor.

* PhD, FRSC, Professor do Departamento de Psiquiatria, Faculdade de Medicina, Universidade de Toronto, Ontário, Canadá. populações heterogêneas no que diz respeito a tratamento (um erro do tipo II significa a aceitação da hipótese nula quando ela é falsa). O presente artigo considera vários desses compostos esquecidos, mas possivelmente eficazes, que foram retirados do mercado sob circunstâncias um tanto especiais. O Estudo da Eficácia de Drogas (Drug Efficacy Study) da Academia Nacional de Ciências (National Academy of Sciences, NAS) e do Conselho Nacional de Pesquisa (National Research Council, NRC), de 1966-1968, e sua implementação pela food and Drug Administration (FDA) norte-americana nos anos de 1968-1974, conhecida pelo acrônimo burocrático DESI (Drug Efficacy Study Implementation ou Implementação do Estudo da Eficácia de Drogas), causou uma redução maciça na farmacopéia desse país.

\section{O ESTUDO DA EFICÁCIA DE DROGAS (DRUG EFFICACY STUDY)}

Em acordo com as provisões das Emendas Kefauver-Harris de 1962 ao Food, Drug and Cosmetic (FDC) Act (Ato da Alimentação, Droga 
e Cosmética) ${ }^{2}$, a FDA comprometeu-se a avaliar a eficácia de todos os produtos farmacêuticos comercializados entre 1938 e 1962. (Do Ato FDC original, de 1938, até a passagem das Emendas, em 1962, a FDA considerou apenas o quesito segurança na aprovação das drogas; a maioria das drogas lançadas antes de 1938 e que ainda estavam no mercado nos anos 60 foram retroativamente aceitas como presumivelmente seguras e eficazes).

Devido à grandeza da tarefa, a FDA ofereceu um contrato de US\$834.000 à NAS/ NRC para que fosse levada a cabo a revisão ${ }^{3}$. Entre 1966 e 1968, os 30 painéis de especialistas da NAS/NRC avaliaram a eficácia presumida de milhares de compostos farmacêuticos. Contudo, a avaliação não comportou o número total de produtos no mercado, e sim apenas aqueles para os quais a FDA havia solicitado revisões.

Uma análise adicional ocorreu, então, quando os reguladores da FDA consideraram as recomendações do Estudo da Eficácia de Drogas e começaram a implementá-las ${ }^{4}$. A DESI resultou em uma espécie de "capinação" em massa do mercado farmacêutico norteamericano. Das 3.443 drogas consideradas pelos painéis, $35 \%$ foram finalmente retiradas como resultado da ação reguladora ${ }^{5}$.

O processo DESI nunca foi objeto de um estudo acadêmico aprofundado. Autores anteriores que se dedicaram a relatar os esforços da FDA 6 para "limpar" a farmacopéia não investigaram os arquivos da FDA nem revisaram sistematicamente o registro dia a dia dos eventos, oferecido no boletim informativo farmacêutico Folha Rosa (Pink Sheet). Constrangida talvez pela extensa natureza de seu próprio trabalho manual, a FDA nunca publicou uma lista abrangente das drogas que tinha banido. Ao invés disso, retiradas individuais foram anunciadas em edições dispersas do Registro Federal (Federal Register), uma fonte geralmente consultada apenas por advogados. Uma visão abrangente da DESI pode ser obtida apenas pelo pareamento das decisões anunciadas no Registro Federal com as decisões originais dos painéis NAS/NRC, documentos que estão agora disponíveis nos arquivos da FDA. O presente artigo realiza esse pareamento.

\section{O PAINEL PSIQUIÁTRICO (PSYCHIATRY PANEL)}

Em debate aqui está apenas o trabalho do Painel Psiquiátrico, que foi presidido pelo psiquiatra de Chicago Daniel Freedman e que incluía alguns dos mais distintos psicofarmacologistas da nação: Jonathan Cole, então na Universidade Tufts e anteriormente organizador do Centro do Serviço de Psicofarmacologia (Psychopharmacology Service Center) do Instituto Nacional de Saúde Mental (National Institute of Mental Health); David Engelhardt, um psiquiatra do campus de Brooklin da Universidade do Estado de Nova Iorque (State University of New York); Leo Hollister, do Hospital de Veteranos de Palo Alto, Califórnia, um homem que em retrospecto pode ser chamado de decano da psicofarmacologia norte-americana; Sidney Merlis, do Hospital do Estado de Nova Iorque (New York State Hospital), em Central Islip; e Karl Rickels, da Universidade da Pensilvânia, um importante expert em ensaios com drogas nos Estados Unidos $^{2}$. Entretanto, a experiência desses indivíduos altamente capacitados era voltada para a psiquiatria asilar e acadêmica, e não para o cuidado primário. Deve-se levar em consideração que, em 1967, na fase intermediária do trabalho do Painel Psiquiátrico, $70 \%$ dos psicotrópicos eram prescritos por médicos generalistas e internistas ${ }^{7}$.

Todos os painéis da NAS/NRC haviam sido instruídos pela FDA para classificar as drogas de acordo com categorias bem definidas: efetiva, provavelmente efetiva, possivelmente efetiva e não-efetiva. As próprias categorias foram tudo menos pilares de exatidão científica, e "provavelmente efetiva", por exemplo, foi freqüentemente utilizada como resultado de divergência de opinião em um painel. Falou William Barclay, membro de um painel: "se apenas um dos membros do painel considerasse a droga efetiva, você chegava a um acordo e a considerava 'provavelmente efetiva'. Você sabe como funcionam comitês"8.

O que os painéis não sabiam, entretanto, era que, ao implementar o estudo, a FDA iria insistir para que drogas provavelmente e possivelmente efetivas fossem retiradas do mercado em uma questão de meses, a menos que a companhia mostrasse evidências convincentes de eficácia oriundas de ensaios controlados $^{9}$. Classificações tais como possivelmente efetiva e provavelmente efetiva acabaram se tornando sentenças de morte se a companhia não estivesse interessada em patrocinar grandes ensaios controlados imediatamente. $E$, nos meses que se 
seguiram à divulgação dos achados da DESI, tais ensaios se tornaram exceção ao invés de regra, na medida em que as companhias contrataram pesquisadores acadêmicos desinteressados (realizar ensaios apenas para a aprovação reguladora nunca atraiu muitos farmacologistas acadêmicos). "Não existem investigadores clínicos suficientes nesse país para levarem a cabo todos os estudos que serão demandados das companhias farmacêuticas", disse George de Stevens, Diretor de Pesquisa da CIBA, à Associação Nacional de Escritores Científicos (National Association of Science Writers) em $1971^{10}$.

Dessa forma, o Painel Psiquiátrico reuniuse para considerar a evidência. O objetivo era fazer julgamentos com base em dados científicos robustos, isto é, ensaios duplocegos bem controlados. Entretanto, como tais estudos sobre produtos psicofarmacológicos começaram a ser realizados apenas por volta de 1955, poucas drogas apresentavam um dossiê com esse tipo de evidência. E os ensaios que haviam sido realizados eram freqüentemente desprovidos de poder estatístico e baseados em populações clínicas que eram tudo menos homogêneas. No entanto, o Painel aceitou evidências negativas oriundas desses ensaios como provas convincentes de ineficácia. Por exemplo, eles consideraram o captodiame (Suvren da Ayerst; Covatin da Lundbeck) pouco efetivo ${ }^{11}$, principalmente com base na evidência negativa de um ensaio crossover controlado em 17 idosos com inquietação - uma população notoriamente heterogênea ${ }^{12}-$, ignorando dois relatos bastante entusiásticos disponíveis que também tinham um pequeno número de pacientes, mas cujos resultados eram bons ${ }^{13,14}$.

O Painel não foi tão rígido com muitas das drogas com as quais os membros psiquiatras tinham familiaridade, isto é, os poucos antidepressivos tricíclicos então no mercado e vários antipsicóticos fenotiazínicos. Entretanto, como observado, a maioria dos compostos farmacêuticos eram prescritos por médicos de família e por internistas em cuidado primário, e não por psiquiatras universitários e asilares, e os painelistas possuíam pouca experiência direta com "antineuróticos", para utilizar um termo corrente na época, significando as drogas para depressão e ansiedade social que começaram a ser disponibilizadas na metade da década de 50, com a chegada do meprobamato.

Algumas das drogas retiradas do mercado mereceram genuinamente seu destino, uma vez que está claro, a partir de evidências tanto qualitativas quanto quantitativas, que elas tinham pouca eficácia e que muitas indicações haviam sido herdadas de outra era. O butabarbital, por exemplo (embora não retirado), tinha sido indicado para a "histeria simples"15. Entretanto, diversas drogas antineuróticas foram rejeitadas primariamente porque ensaios controlados de eficácia não haviam sido realizados para elas. Mas existem outras evidências, tais como extensos estudos abertos, de que algumas dessas drogas eram de fato eficazes e não mereciam ser retiradas. Hoje em dia, esses compostos foram amplamente esquecidos.

O presente artigo considera algumas dessas drogas e a evidência naturalística (baseada na experiência) de sua eficácia, do ponto de vista da descoberta de drogas hoje. Não é proposto que essas drogas, que estão há muito sem patente, sejam reavivadas, mas, em vez disso, que se encoraje outros pesquisadores a estudarem seus perfis de receptor, na esperança de que identifiquem compostos patenteáveis com perfis similares e que estão agora na "prateleira" - ou que sejam capazes de ser sintetizados.

\section{"JOGAR O BEBÊ FORA JUNTO COM A ÁGUA DO BANHO" (BABY OUT WITH THE BATHWATER)}

No final das contas, $48,5 \%$ das drogas psicotrópicas foram retiradas do mercado norte-americano pela FDA, em grande parte como resultado das recomendações do Painel Psiquiátrico (tabela 1): quase metade dos fármacos psiquiátricos americanos foram considerados pouco efetivos. As categorias que sofreram a maior restrição foram os produtos combinados, como o Deprol da Carter-Wallace, uma mistura de meprobamato e benzactizina ${ }^{16}$. Já entre os produtos de componentes únicos, o golpe mais duro foi nos antineuróticos. A FDA acabou por retirar 13 dos 18 antineuróticos que foram avaliados pelo Painel Psiquiátrico. Seriam todas essas drogas que foram rejeitadas realmente tão ineficazes? 
Tabela 1 - Drogas psiquiátricas avaliadas pelo Painel Psiquiátrico da NAS/NRC*

\begin{tabular}{lccc}
\hline \multicolumn{1}{c}{ Tipo } & $\begin{array}{c}\text { Número total considerado } \\
\text { pelo Painel }\end{array}$ & $\begin{array}{c}\text { Número posteriormente } \\
\text { retirado }\end{array}$ & $\%$ retirada \\
Antineuróticos & 18 & $13 \dagger$ & 72,2 \\
Antipsicóticos & 13 & 2 & 15,4 \\
Barbituratos & 4 & 0 & - \\
Estimulantes & 9 & 1 & 11,1 \\
IMAOs & 3 & 1 & 33,3 \\
Antidepressivos tricíclicosł & 2 & 0 & - \\
Drogas de combinação & 19 & 16 & 84,2 \\
Totais & 68 & 33 & 48,5 \\
\hline
\end{tabular}

NAS = National Academy of Sciences; NRC = National Research Council; IMAOs, inibidores da monoamino-oxidase; FDA = Food and Drug Administration (EUA).

* As drogas foram avaliadas entre 1966 e 1968 e foram subseqüentemente retiradas do mercado pela FDA nos anos de 1968 a 1974.

† Inclui a buclizina, admitida como efetiva para náusea; indicações psiquiátricas foram retiradas.

‡ Imipramina, amitriptilina.

Há evidências de que, pelo menos com alguns dos antineuróticos, o Painel "jogou o bebê fora junto com a água do banho". Por exemplo, os cinco membros consideraram os tabletes de Spartase da Wyeth apenas como possivelmente efetivos, o que significava que a droga teria que ser retirada dentro de 6 meses, a menos que a empresa fornecesse provas convincentes de eficácia ${ }^{17}$. O Spartase, uma mistura de aspartato de potássio e aspartato de magnésio, foi inicialmente comercializado em 1961 como um agente antifatigante, e a Wyeth teria dito que tinha grandes planos para o composto, que era conhecido por alguns por ser uma droga potencial para o tratamento daa disfunção sexual masculina ${ }^{18}$, antes da FDA forçar sua retirada em $1970^{19}$.

A combinação genérica dos sais de aspartato tem, desde então, tido grande sucesso na medicina alternativa. Uma recente busca no Yahoo! por magnesium potassium aspartate produziu 9.320 sites, muitos deles preocupados com terapia de quelação e com a síndrome da fadiga crônica.

Qual é a evidência para a eficácia do aspartato como um antineurótico? Palma Formica, uma médica de família de Woodbridge, Nova Jérsei, que caracterizou a "síndrome da dona de casa" (housewife's syndrome), fez um estudo longitudinal crossover uni-cego versus placebo com 26 pacientes de sua clínica que relataram sintomas somáticos vagos em associação a fadiga. Não houve efeito da droga em nenhum dos períodos de placebo - realmente, ela mal podia convencer os pacientes que tomavam placebo a continuar - mas $87 \%$ dos pacientes no tratamento ativo tiveram uma resposta positiva. "A mudança era surpreendente nos pacientes que responderam", informou ela, "eles ficaram alertas, alegres, animados e energéticos e caminhavam com passos firmes, vivos. Eles declararam que o sono os renovou como não fazia há meses... A exaustão matutina tinha acabado completamente"20. Esses são de fato resultados bastante impressionantes, embora o tamanho da amostra e a duração da pesquisa não tenham seguido o padrão da FDA. (Não é de se estranhar que o Painel Psiquiátrico tenha considerado o estudo como tendo "sérios erros de metodologia".) Mas a combinação de sais de aspartato pareceu ter algum tipo de efeito terapêutico. Que perfil de receptor ela teve?

O Painel Psiquiátrico estava indeciso com relação ao emilcamato da Merck (Striatran) e questionou a declaração da empresa de que ele poderia ser satisfatório no tratamento de ansiedade e tensão: "O Painel não está seguro sobre o que se entende por ansiedade e tensão ocorrendo separadamente" ${ }^{21}$. O emilcamato era um carbamato, cuja patente a Merck tinha adquirido em 1912. A substância foi considerada efetiva o bastante para que a A/B Kabi Company de Estocolmo fizesse um registro sueco de patente em 1957 e uma patente norte-americana em 196122. A Merck começou a comercializar o emilcamato em 1960 como "um novo, avançado, potente relaxante para ansiedade e tensão", superior ao meprobamato ${ }^{23}$, o qual, na ocasião, somente 1 ano após o lançamento de 
Figura 1 - Drogas antineuróticas avaliadas pelo Painel Psiquiátrico NAS/NRC, 1966-1968: posteriormente, 13 de um total de 18 drogas foram retiradas pela FDA

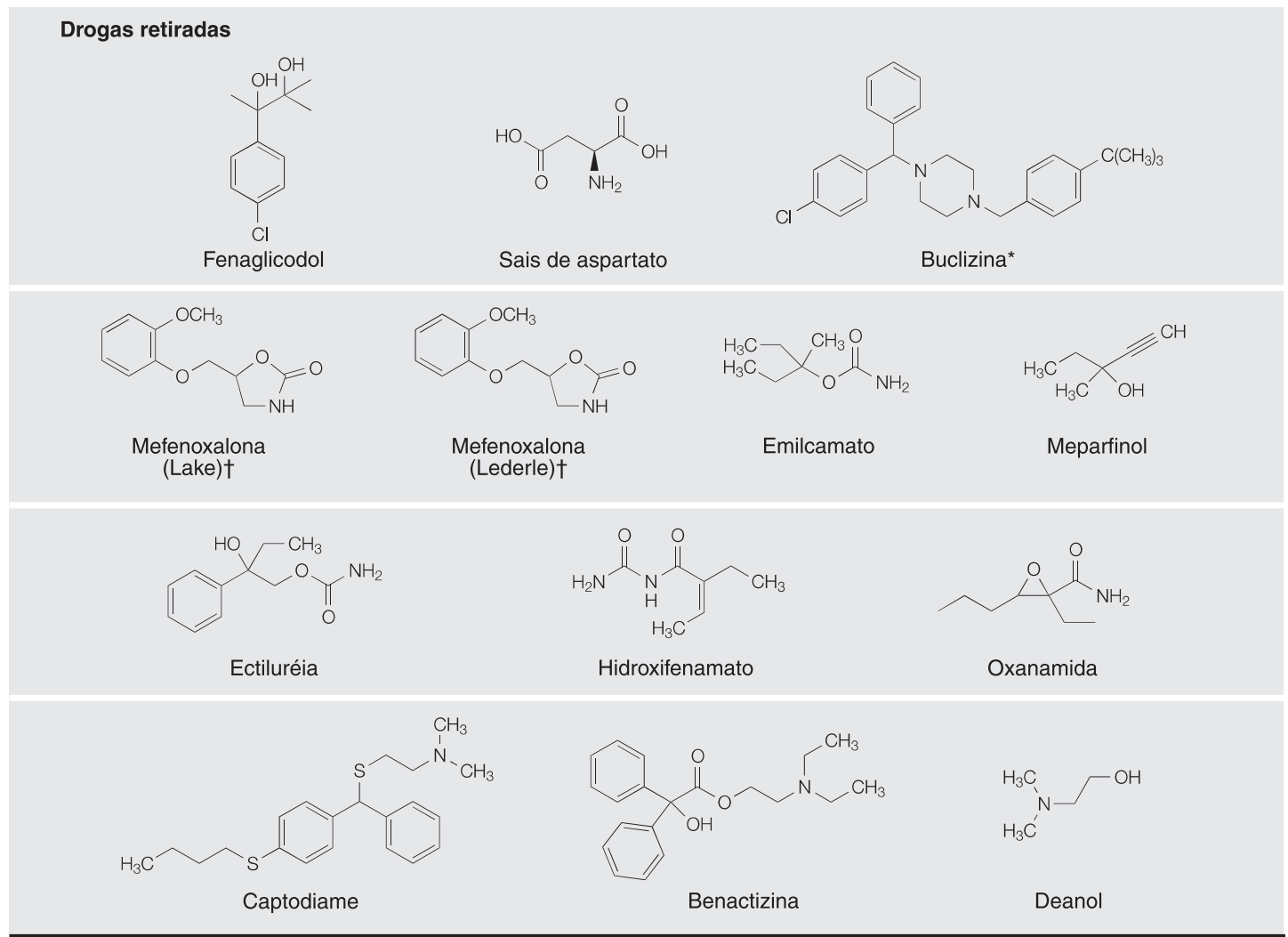

Drogas não retiradas

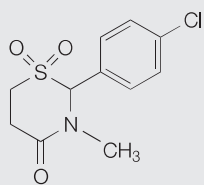

Clormezanona

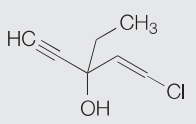

Etclorvinol

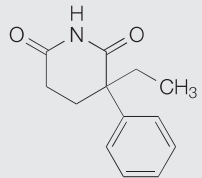

Glutetimida

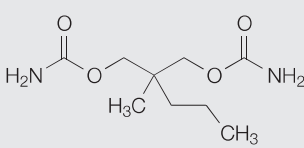

Meprobamato

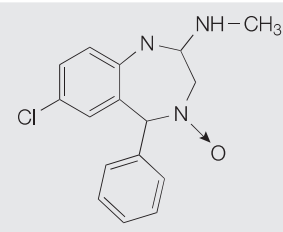

Clordiazepóxido

Um composto sem nenhuma indicação de ser "efetivo" seria retirado do mercado.

* A buclizina foi considerada efetiva somente para náusea.

† Duas empresas (Lake e Lederle) apresentaram a mefenoxalona para diferentes indicações, e a avaliação do Painel Psiquiátrico foi feita por indicação, e não pelo composto como um todo.

NAS = National Academy of Sciences NRC = National Research Council; FDA = Food and Drug Administration (EUA). 
clordiazepóxido (Librium), ainda dominava o mercado ansiolítico.

Qual a evidência para a eficácia de emilcamato? Entre outros estudos, na Filadélfia, Harry, Shubin \& Nathan Steinberg fizeram um estudo semicontrolado com 400 pacientes ambulatoriais e internados em uma clínica, os quais apresentavam uma série de diagnósticos, desde psiconeuroses até psicoses $^{24}$. O estudo teve três braços: emilcamato, meprobamato e placebo, mas eles não continuaram com o placebo depois do $50^{\circ}$ paciente e não digitaram seus resultados, porque os pacientes reconheceram rapidamente que estavam na condição placebo. Entre os 324 pacientes que apresentavam psiconeuroses, $72,3 \%$ tiveram uma boa ou excelente resposta com emilcamato, comparados a $64 \%$ daqueles que estavam com meprobamato. Poucos pacientes psicóticos responderam a qualquer uma das drogas. Os autores concluíram: "o emilcamato é uma droga efetiva para o tratamento dos estados de ansiedade"24. Novamente, pela falta de escalas de avaliação e pela interrupção prematura do placebo, esse não foi um estudo capaz de esclarecer as restrições da FDA. Porém, ele indica que a droga tinha algo a oferecer e que seria interessante aprender seu perfil de receptor.

Por fim, uma das drogas entre os 13 antineuróticos retirados mereceria um escrutínio hoje: o hidroxifenamato, um carbamato patenteado em 1962 pela Armour Pharmaceutical e comercializado um ano antes, em 1961, como Listica, "o primeiro tensitrópico seletivo"25.

Qual a evidência relacionada ao hidroxifenamato? Existem alguns dados quantitativos ligeiramente interessantes que 0 Painel Psiquiátrico não levou em consideração por serem oriundos de "um simpósio organizado pela empresa patrocinadora" 26 (se todo esse tipo de evidência fosse dispensado hoje, a psicofarmacologia deixaria de existir). No simpósio, Blaine McLaughlin et al. apresentaram evidências de um estudo crossover de três braços envolvendo Listica, Librium (clordiazepóxido) e placebo em pacientes ambulatoriais da Clínica de Psiquiatria da Faculdade de Medicina da Mulher na Filadélfia (Psychiatry Clinic of the Women's Medical College in Philadelphia). Um total de 24 pacientes completaram o estudo. Na fase Listica, 18 dos 24 responderam bem; 19 dos 24 responderam bem na fase do Librium; e 9 de 24 responderam bem na fase placebo ${ }^{27}$.
Os dados qualitativos - testemunhos dados no simpósio patrocinado pela empresa, no qual os resultados foram apresentados - são mais interessantes ainda. Edward Greenspan, um cardiologista da Faculdade de Medicina de Nova lorque (New York Medical College), referiu que a droga ajudava seus pacientes hipertensos a relaxar: "Tentei Librium. Tentei nialamida e Tofranil (imipramina). Não encontrei bons resultados em pessoas com mais de 55 e 60 anos de idade. Não achei que a monoaminaoxidase tivesse me ajudado tanto quanto um tranqüilizante desse tipo"28. De acordo com Leo Alexander, um conhecido psiquiatra de Boston e especialista em terapias físicas: "Talvez a maior vantagem da droga seja sua suavidade. Não há nenhuma outra droga que tenha esses efeitos, a não ser a benactizina"29.

Esses comentários e estatísticas insignificantes não representam, é claro, prova definitiva da eficácia do hidroxifenamato. Mas eles sugerem que um segundo olhar poderia valer a pena: a droga estava claramente tendo algum efeito, e se seu mecanismo de ação pudesse ser identificado, a descoberta de drogas na psicofarmacologia poderia avançar.

\section{DISCUSSÃO}

Está claro, retrospectivamente, que algumas drogas que foram descartadas pelo Painel Psiquiátrico poderiam ser efetivas. A Associação dos Fabricantes e de Pesquisa Farmacêutica (Pharmaceutical Research and Manufacturers Association) mostrou esse aspecto para a Revisão NAS/NRC como um todo, que testemunhou um verdadeiro massacre de inocentes entre as empresas farmacêuticas americanas: "Muitos dos produtos colocados nas categorias qualificadas foram de fato considerados por membros dos painéis como sendo efetivas... Em muitos casos, uma modificação no rótulo, e não a efetividade do medicamento, estava em discussão"30. Daniel Freedman, chefe do Painel Psiquiátrico, concordou que o Painel tinha ido muito além em sua insistência na presença de estudos controlados como uma pré-condição para manter as drogas no mercado. Ele disse para o Congresso: "Existem algumas drogas [psicotrópicas] muito boas apoiadas por poucos dados objetivos". Ele sugeriu que estava "sob responsabilidade da FDA" a implementação cuidadosa das recomendações do Painel ${ }^{31}$.

Há uma lição para os nossos tempos sobre o excesso de confiança em estudos controlados. Um bom dado proveniente de um 
caso isolado ou dados sólidos de estudos abertos não constituem automaticamente "um atestado de evidência", sendo muito temidos na farmacologia moderna em função de uma época na qual médicos "barbudos da fronteira" exageravam na prescrição de xaropes para tosse repletos de codeína. Como Alvan Feinstein, o notável epidemiologista da Universidade McMaster, referiu em um seminário sobre Filosofia e Tecnologia de Avaliação de Drogas (Philosophy and Technology of Drug Assessment), em 1972: "Nós nos encaixotamos em uma abordagem metodológica rígida para avaliar qualquer tipo de terapia... Nós vamos nos ver em dificuldades terríveis... se continuarmos nos iludindo ao pensar que utilizar o método duplo-cego randomizado deve ser nossa única preocupação. Até o dia em que percebermos que todos esses importantes dados humanísticos estão sendo deliberadamente ignorados, inadvertidamente abandonados, ou não corretamente ajustados e analisados, nós continuaremos amarrados em uma forma desumanizada de pseudociência"32.

O farmacologista Louis Lasagna, consciente da falsa aventura da DESI, acrescentou a essa discussão: "Não estou querendo jogar fora uma vasta experiência naturalística com base em um ou dois estudos duplo-cegos negativos. Tenho visto estudos duplo-cegos negativos em demasia"32.

Outros investigadores acadêmicos distintos fizeram críticas semelhantes à auditoria NAS/ NRC e à aplicação inflexível de seus resultados pelos reguladores da FDA. A evidência em favor das drogas discutidas neste artigo é considerável, embora não na forma de estudos controlados. Seu mecanismo de ação merece um segundo olhar, na esperança de que sejam desenvolvidos fármacos verdadeiramente efetivos para o tratamento de transtornos de humor e de ansiedade.

Concluindo, o passado é um grande armazém de compostos de uso potencial no futuro da psicofarmacologia. Muitas outras drogas que foram sintetizadas nos Estados Unidos e na Europa na primeira metade do século 20 e então esquecidas - drogas longe da visão do Estudo de Eficácia de Drogas da NAS/NRC - oferecem uma promessa de eficácia. Numa época em que literalmente bilhões de dólares estão sendo desperdiçados sem sucesso na descoberta de novos compostos psicoativos, seria uma vergonha se algumas dessas raridades não fossem reexaminadas para ver como elas funcionavam.

\section{Agradecimento}

O Conselho Editorial da RPRS agradece a Anna Virginia Williams e Marcelo T. Berlim pela tradução deste artigo.

\section{REFERÊNCIAS BIBLIOGRÁFICAS}

1. Shorter E. Fading beauties: searching for value in psychopharmacology. Scrip Magazine 2001; September: 52-3.

2. Drug Efficacy Study. Final Report to the Commissioner of Food and Drugs, Food and Drug Administration, from the Division of Medical Sciences, National Research Council. Washington DC: National Academy of Sciences; 1969.

3. Impact of NAS/NRC report on future of drug regulation. The Pink Sheet 5 (July 14, 1969).

4. Bryan PA, Stern LH. The drug efficacy study, 1962-1970. FDA Papers 1970;4:14-7.

5. Temple R. Re-evaluation of marketed drugs: the DESI Program. 3rd International Conference of Drug Regulatory Agencies: Stockholm, Sweden; 1984.

6. Temin P. Taking your medicine: drug regulation in the United States. Cambridge: Harvard University Press; 1980.

7. Nelson hearings on psychotropics open with NIMH. The Pink Sheet T\&G-6 (July 14, 1969).

8. Edwards' new thinking on Rx combos emerges from House subcommittee. The Pink Sheet 28 (May 10, 1971).

9. Smith Kline \& French Laboratories. A chronology and review of the National Academy of Sciences/National Research Council Drug Efficacy Study. Philadelphia: Smith Kline \& French; 1971

10. NAS should reconvene drug evaluation panel chairmen. The Pink Sheet T\&G-6 (October 19, 1970).

11. National Academy of Sciences/National Research Council. NAS/NRC Report on Captodiame FDA Accession Number 1740 (1968).

12. Ashby WR, et al. A clinical trial of covatin on elderly patients with anxiety and restlessness. J Ment Sci1959;105:504-7.

13. Ellermann M. Virkningen af covatin (et nyt dagsedativum) pa et ambulant patientmateriale. Nordisk Medicin 1955;10:1531.

14. Pentney $\mathrm{BH}$, et al. Captodiame in anxiety states in general practice. Practitioner1960;185:218-21.

15. National Academy of Sciences/National Research Council. NAS/NRC Report on Butabarbital FDA Accession Number 1720 (1968)

16. National Academy of Sciences/National Research Council. NAS/NRC Report on Deprol FDA Accession Number 1729 (1968).

17. National Academy of Sciences/National Research Council. NAS/NRC Report on Potassium-Magnesium Aspartate FDA Accession Number 1314 (1968).

18. Wright J. An interview with Dr Jonathan Wright Tahoma Clinic [online] (cited Oct 10 2002). Available from: http:// www.tahoma-clinic.com/male.shtm.

19. Hass AE, Coppinger PL. Introductions and discontinuations of new drugs in the United States and the United Kingdom. Food and Drug Administration, Office of Planning and Evaluation, Study 78 Appendix A, September 1989

20. Formica PE. The housewife syndrome. Treatment with the potassium and magnesium salts of aspartic acid. Curr Therap Res 1962;4:98-106. 
21. National Academy of Sciences/National Research Council. NAS/NRC Report on Emylcamate FDA Accession Number 1739 (1968).

22. Melander BO, et al. 3-Methyl-3-pentanol carbamate compositions. US Patent 2,972,564 (1961).

23. Striatran advertisement. JAMA 1960;174:234-5.

24. Shubin $\mathrm{H}$, Steinberg $\mathrm{N}$. A study of a new tranquilizer in general practice: emylcamate in 400 patients. Curr Therap Res 1963;3:527-33.

25. Listica advertisement. Dis Nervous Syst 1961;22:543-5.

26. National Academy of Sciences/National Research Council. NAS/NRC Report on Hydroxyphenamate FDA Accession Number 1737 (1968)

27. Mclaughlin BE, et al. A double blind study involving Listica, Librium and placebo as an adjunct to supportive psychotherapy in a psychiatric clinic. Dis Nervous Syst 1961;22:S41-2

28. Greenspan EB. Use of hydroxyphenamate in some forms of cardiovascular disease. Dis Nervous Syst 1961;22:S33-4.

29. Alexander L. Discussion comment. Dis Nervous Syst 1961;22:S53

30. PMA President Stetler's statement on efficacy study disclosures. The Pink Sheet 9 (June 14, 1971).

31. Justice's narcotics bill called 'stupid': Brill urged government-supported drug data. The Pink Sheet 10 (August 4, 1969).

32. Cooper JD. The Efficacy of Self-Medication. Washington, DC: The Smithsonian Institution, Interdisciplinary Communications Program; 1973.

\section{RESUMO}

A história da psicofarmacologia é repleta de erros do tipo II - a rejeição de compostos efetivos baseada na crença enganosa de que eles foram ineficazes por não terem vencido o placebo em um ensaio clínico controlado. A revisão de algumas dessas drogas para estabelecer seu perfil de receptores e para determinar quais os compostos patenteáveis que atualmente estão na "prateleira" e que encaixam nesse perfil pode representar um caminho futuro possível para a descoberta de drogas. Este artigo examina as circunstâncias especiais nas quais inúmeras drogas potencialmente efetivas foram retiradas do mercado nos Estados Unidos.

Descritores: Psicofarmacologia, descoberta de drogas, receptores.

\section{ABSTRACT}

The history of psychopharmacology is littered with type II errors - the rejection of effective compounds in the specious belief that they were inefficacious because they had failed to beat placebo in a controlled trial. Revisiting some of these drugs to establish their receptor profile, and then determining what patentable compounds now on the shelf match that profile, might represent a possible future pathway to drug discovery. This article looks at the special circumstances in which numerous potentially effective drugs were withdrawn in the United States.

Keywords: Psychopharmacology, drug discovery, receptors.

Title: Looking backwards: a possible new pathway for drug discovery in psychopharmacology

\section{RESUMEN}

La historia de la psicofarmacología está llena de errores de tipo II - el rechazo de compuestos efectivos basado en la creencia equivocada de que ellos han sido ineficaces porque no han vencido el placebo en un ensayo clínico controlado. La revisión de algunas de esas drogas para establecer su perfil de receptores y para determinar cuales son los compuestos patentables que actualmente están en la "estante" y que se encajan en ese perfil puede representar un camino futuro posible para la descubierta de drogas. Este artículo analiza las circunstancias especiales en las que innumerables drogas potencialmente efectivas han sido retiradas del mercado en Estados Unidos.

Palabras clave: Psicofarmacología, descubierta de drogas, receptores.

Título: Mirando hacia atrás: un nuevo camino posible para la descubierta de drogas en psicofarmacología

Endereço para correspondência:

Faculty of Medicine, University of Toronto 88 College Street, Toronto, M5G 1LY, Canada E-mail: eshorter@charter.net

Copyright () Revista de Psiquiatria do Rio Grande do Sul - SPRS 